\title{
OS DISCURSOS SOBRE CURRÍCULO E AS CONCEPÇÕES DE AVALIAÇÃO NOS I E II SEGMENTOS DO ENSINO FUNDAMENTAL DA REDE MUNICIPAL DE JOÃO PESSOA/PB
}

\author{
Maria Zuleide da Costa Pereira ${ }^{1}$ \\ Francisco Alex Pereira Soares ${ }^{2}$ \\ Gessica Mayara de Oliveira Souza ${ }^{3}$ \\ Rafael Ferreira de Souza Honorato ${ }^{4}$
}

\section{RESUMO}

O presente texto aborda o plano II do projeto intitulado CURRÍCULO E AVALIAÇÃO: discursos contemporâneos (Os discursos sobre currículo e as concepções de avaliação nos I e II segmentos do Ensino Fundamental da Rede Municipal de João Pessoa/PB), realizado pelo programa PIBIC/PIVIC concretizado no período de 2014/2015, tendo como objetivo uma análise dos sentidos de avaliação e como estes estão articulados com os sentidos de currículo nas escolas municipais de João Pessoa. Para tanto e objetivando o alcance do objetivo proposto, esta pesquisa aproxima-se de autores do campo do currículo, como Pereira (2009a, b) que assume o currículo como redes de significações, bem como em outros autores desse campo de estudo: Moreira e Candau (2007), Silva (2013). No tocante à avaliação, está embasada em Fernandes e Freitas (2007), Mainardes (2010), Esteban (2010). A pesquisa assume características quanti-qualitativa, de campo, bibliográfica, documental, exploratória e explicativa de acordo com Gonçalves (2003) e Marconi e Lakatos (2003). Para a compreensão dos sentidos de avaliação nos documentos analisados, foi utilizada a linguística de corpus, baseada nos estudos de Sardinha $(2000,2009,2006)$ e, para auxiliar na linguística de corpus, foi utilizado o programa WordSmith Tool 6. Para a compreensão dos sentidos, lançou-se mão da Teoria do Discurso de Laclau (2005) e Laclau e Mouffe (2004) e de estudos de autores que se fundam nessa teoria, como Pereira (2009 a, b), Mendonça (2009), Ferreira (2011), entre outros. Os documentos analisados foram a Lei de Diretrizes e Bases da Educação, Diretrizes Curriculares Nacionais para o Ensino Fundamental, Parâmetros Curriculares Nacionais, Plano Municipal de Educação de João Pessoa, PPP de escolas da rede de ensino municipal de João Pessoa/PB e entrevistas feitas com professores. Foram utilizados trabalhos anteriores realizados com o intuito de saber os sentidos de currículo nas escolas da rede de ensino municipal de João Pessoa e realizada a análise do imbricamento de sentidos entre currículo e avaliação, em que se percebeu haver uma relação entre essas categorias, na concepção de que ambas podem ser consideradas significantes vazios sob a luz da Teoria do Discurso.

Palavras-chaves: Educação. Currículo. Avaliação. Ensino Fundamental.

\footnotetext{
${ }^{1}$ Professora Associada IV do CE/UFPB, vinculada ao Programa de Pós-Graduação em Educação da UFPB, mzuleide@ce.ufpb.br

${ }^{2}$ Graduando em Pedagogia pela UFPB, Bolsista da Iniciação Científica em 2014/2015. Alexsoares0707@gmail.com

3 Graduanda em Pedagogia pela UFPB, Voluntária da Iniciação Científica em 2014/2015, gessicamayara04@gmail.com

${ }^{4}$ Graduando em Pedagogia pela UFPB, Bolsista da Iniciação Científica em 2013/2014/2015., rafaelhono@gmail.com
} 


\title{
SPEECHES ON THE CURRICULUM AND CONCEPTS IN EVALUATION OF I AND II SEGMENTS OF MUNICIPAL NETWORK BASIC EDUCATION OF JOÃO PESSOA / PB
}

\begin{abstract}
This paper addresses the plan II of this Project entitled CURRICULUM AND EVALUTION: contemporary discourses (Discourses about curriculum and the concepts evaluation in I and II segments of Municipal Elementary Education of João Pessoa/PB) conducted by PIBIC/PIVIC program realized in the period of 2014/2015, with the objective of analysis of the meanings of evaluation and how these are articulated with the meanings of curriculum in public schools in João Pessoa. For this purpose and aiming to achieve the proposed objective, this research approaches to curriculum field's authors, as Pereira $(2009 a, b)$ who takes on the curriculum as a network of meanings, as well as other authors of this study field: Moreira and Candau (2007), Silva (2013). As regards the evaluation is grounded in Fernandes and Freitas (2007), Mainardes (2010), Esteban (2010). The survey takes quantitative and qualitative characteristics, field, bibliographical, documentary, exploratory and explanatory according to Gonçalves (2003) and Marconi and Lakatos (2003). To understand the meanings of evaluation in documents examined, we used the corpus linguistics, based on studies of Sardinha $(2000,2009,2006)$ and to assist in corpus linguistics, it was used WordSmith Tool 6 program. To understand the meanings, used Speech's Theory of Laclau (2005) and Laclau and Mouffe (2004) and studies of authors that are based on this theory, as Pereira (2009a, 2009b), Mendonça (2009), Ferreira (2011), among others. The documents analyzed were the Law of Directives and Bases of Education, National Curriculum Guidelines for Elementary Education, National Curriculum Parameters, João Pessoa's Municipal Education Plan, PPP of local schools of João Pessoa/PB and interviews with teachers. Previous work were used in order to know the curriculum meanings in schools in the municipal school system of João Pessoa and performed the analysis of overlapping with the essence of curriculum and evaluation in that it was perceived to be a relationship between these categories, in the conception that both can be considered empty significant in the light of Speech's Theory.
\end{abstract}

Keywords: Education. Curriculum. Evaluation. Elementary Education.

\section{INTRODUÇÃO}

As reflexões acerca dos campos de currículo e avaliação são questões centrais nas pesquisas, bem como em teorias pedagógicas e na formação de professores, seja ela inicial ou continuada. Este texto é fruto da execução do projeto do Programa Institucional Bolsista de Iniciação Científica (PIBIC), ocorrido no de período de 2014 a 2015, intitulado AVALIAÇÃO E CURRÍCULO DISCURSOS CONTEMPORÂNEOS, objetivando verificar os sentidos sobre currículo e avaliação presentes nos documentos oficiais da educação brasileira, nos Projetos PolíticoPedagógicos (PPPs) das escolas e nos discursos dos professores. O projeto de pesquisa foi dividido em três planos, sendo este texto sobre "Os discursos sobre currículo e as concepções de avaliação nos I e II segmentos do Ensino Fundamental da Rede Municipal de João Pessoa/PB".

O objetivo presente no projeto era analisar os sentidos de avaliação e como estes estão articulados com os sentidos de currículo nas Escolas da Rede Municipal de Ensino de João Pessoa/PB, especificamente nos segmentos I e II do Ensino Fundamental. Para tanto, o objetivo proposto foi destrinchado em outros que se referem aos objetivos específicos, quais 
sejam: I- investigar as palavras fixadoras de sentidos de avaliação nos documentos nacionais e locais; II- analisar os sentidos de avaliação nos discursos dos docentes; III- compreender como os sentidos de currículo e de avaliação, encontrados nos discursos dos docentes e nos documentos oficiais, articulam-se. Tais objetivos se encontram plenamente executados e explanados no texto que se segue.

Visto que Pereira (2009 a) assume que currículo possui múltiplos sentidos, ou redes discursivas de significações, por promover várias articulações como a cultura, etnia, religiosidade, poder, entre outras. Já Fernandes e Freitas (2007) trazem que o professor possui um "certo modo" de ver o mundo, que está intimamente vinculado à cultura e práticas vivenciadas, e este modo de ver o mundo, devido a questões culturais, é estritamente vinculado à ação de classificação e de seleção que, por sua vez, é uma forma de avaliação. Assim, percebemos haver um imbricamento entre currículo e avaliação, a partir do momento em que utilizamos nossos pré-conceitos (sejam eles de origem cultural, religiosos etc.) para avaliar, e o currículo com seus múltiplos sentidos nos ajuda a compreender tais conceitos presentes na avaliação.

A origem da nossa problematização surge dessa articulação entre currículo e avaliação, pois "desse modo são inúmeras as possibilidades de articulação discussão sobre as políticas curriculares e os discursos de avaliação da aprendizagem" (MAINARDES, 2010, p.233).

Para auxiliar na verificação dos sentidos presentes nos documentos analisados e nos discursos dos docentes, lançamos mão do programa Wordsmtih Tool que, baseado em Sardinha $(2009$, p. 86), possui diversas funcionalidades que potencializam a "análise de vários aspectos da linguagem, como a composição lexical, a temática de textos selecionados e a organização retórica e composicional de gêneros discursivos". Utilizamos, também, a Linguística de Corpus, que analisa os dados coletados, uma vez que tal forma de análise de dados consiste na investigação e criação de corpora, que é um conjunto de documentos e transcrições de discursos armazenados em meio digital.

Para a análise e compreensão dos dados coletados, apropriamo-nos da Teoria do Discurso com embasamento em Laclau (2005) e Laclau e Mouffe (2004), através de estudos iniciais em Pereira (2009 a, b) e Mendonça (2008), o que facilitou um melhor entendimento da citada teoria, uma vez que, devido a sua extenção e complexidade, a exiguidade do tempo não nos permitiu fazer um maior aprofundamento.

\section{METODOLOGIA}

Para determinar o caminho metodológico aplicado em nossa pesquisa, baseamo-nos nos estudos de Gonçalves (2003) e Marconi e Lakatos (2003) e, portanto, categorizamos este estudo segundo seus objetivos, a natureza dos seus dados, suas fontes de informação e seus procedimentos de coleta.

Classifica-se a pesquisa segundo os seus objetivos como exploratória e descritiva. De acordo com Gonsalves (2003), a pesquisa exploratória é uma primeira aproximação a um determinado fenômeno que, até então, é pouco explorado, caracterizando-se pelo desenvolvimento e esclarecimento de ideias. Ainda conforme a mesma autora, a pesquisa descritiva "[...] objetiva escrever as características de um objeto de estudo [...]" (GONSALVES, 2003, p. 65). A característica descritiva percebe-se quando buscamos compreender os sentidos de currículo e de avaliação presentes nos documentos nacionais e locais da educação e no discurso do corpo docente da rede de ensino pública municipal. 
O procedimento de coleta classifica-se como de levantamento, bibliográfico e documental, o que nos leva, também, a uma classificação quando às fontes da informação como de campo, bibliográfica e documental. O levantamento de campo deu-se através das entrevistas feitas com o corpo docente da rede municipal de ensino de João Pessoa/PB, que ocorreu através de uma entrevista estruturada. A pesquisa bibliográfica, segundo Marconi e Lakatos (2003, p.158), "[...] é um apanhado geral sobre os principais trabalhos já realizados, revestidos de importância, por serem capazes de fornecer dados atuais e relevantes relacionados com o tema".

Esta é, também, uma pesquisa documental e bibliográfica. Marconi e Lakatos (2003, p.174) explicam "[...] que a fonte de coleta de dados está restrita a documentos, escritos ou não, constituindo o que se denomina de fontes primárias". Assim, foram analisados documentos referentes à regulamentação da educação no Brasil e no Município de João Pessoa/PB. Os documentos que versam sobre a educação em nível nacional que foram explorados em nossa pesquisa foram a Lei de Diretrizes e Bases (LDB) - Lei 9.394 de 20 de dezembro de 1996, os Parâmetros Curriculares Nacionais para o Ensino Fundamental de 19972000 e as Diretrizes Curriculares Nacionais do Ensino Fundamental de 2013. Nos documentos locais que versam sobre a educação de ensino fundamental, buscamos o Plano Municipal de Educação e os PPPs das Escolas Públicas Municipais de Ensino Fundamental. Quanto ao Plano Municipal de Educação, é importante ressaltar que em nossa pesquisa utilizamos o aprovado pela Lei 9.864, de 27 de dezembro de 2002, visto que o novo Plano Municipal da Educação, aprovado ainda no ano (2015) pela Câmara Municipal de João Pessoa/PB, ainda não foi sancionado pelo Chefe da Edilidade Municipal e, portanto, ainda não se encontra vigente. $E$, por fim, trata-se de pesquisa bibliográfica devido à vasta pesquisa feita em diversas publicações sobre os temas em análise.

De acordo com a forma, os dados levantados foram analisados, e nossa pesquisa classifica-se como quanti-qualitativa, pois analisamos como os sentidos de currículo e de avaliação estão presentes nos documentos que versam sobre a educação e no discurso dos docentes que lecionam no Ensino Fundamental da Rede Pública de Ensino.

\section{Linguística de Corpus}

Com os Documentos Nacionais e Locais que versam sobre a educação no Ensino Fundamental segmentos I e II, PPP coletado e entrevista do Corpo Docente da rede municipal de ensino fundamental em mãos, iniciamos a análise dos dados. Primeiramente, fizemos uma leitura minuciosa de todo o material coletado e demos continuidade com ao auxílio da linguística de corpus, através da ferramenta WordSmith Tool 6 para a análise dos dados coletados.

A linguística de corpus, que utilizamos em nossa pesquisa, é uma área de estudos que emerge nas pesquisas, não só em campos da linguística, mas se expandindo para a área da educação e outras áreas ligadas às humanidades. Por ser uma área em expansão e utilização, buscamos trazê-la para nosso trabalho para enriquecê-lo e auxiliar na percepção dos sentidos presentes nos documentos coletados, auxiliando ainda na organização destes.

Sardinha (2009) afirma que a linguística de corpus é um campo que tem se dedicado à criação e analise de corpora, que trata de um conjunto de textos e transcrições de falas guardados em formato digital. Vale ressaltar que, Segundo Sanchez (1995, p. 8-9), 
[...] a expressão corpus refere-se a um conjunto de dados linguísticos (pertencentes ao uso oral ou escrito da língua, ou a ambos), sistematizados segundo determinados critérios, suficientemente extensos em amplitude e profundidade, de maneira que sejam representativos da totalidade do uso linguístico ou de algum de seus âmbitos, dispostos de tal modo que possam ser processados por computador, com a finalidade de propiciar resultados vários e úteis para a descrição e análise.

O Corpus não é formado por qualquer tipo de dados, sendo apenas considerados textos autênticos e que a língua utilizada seja a língua materna, e os textos devem ser naturais. De acordo com Sardinha (2000, p.336), "por textos naturais entende-se 'autênticos', isto é, aqueles que existem na linguagem e que não foram criados com o propósito de figurarem no corpus. Além disso, amplia-se a ideia de 'natural' para incluir somente aqueles textos produzidos por humanos. Desta forma está excluída a produção provinda de programas de geração de textos". Portanto, compreendemos que os textos que formam a corpora devem produzir significados para o pesquisador e que sejam compatíveis com o objeto de pesquisa.

Sardinha (2006) cita quatro pré-requisitos para a formação de um corpus computadorizado:

- Primeiro, o corpus deve ser autêntico e natural e não pode ter sido escrito com a intenção de ser um corpus.

- Segundo, quando se fala em autenticidade, explica-se que os textos devem ser inscritos por falantes nativos.

- Terceiro, é importante que o pesquisador escolha os textos de acordo com regras estabelecidas por ele próprio, para que o texto seja autêntico e natural e tenha a ver com o objeto que está sendo pesquisado.

- $\quad$ O quarto pré-requisito diz respeito à representatividade do corpus. Cabe se perguntar 'representativo do quê?' e 'representativo para quem?'.

O mesmo autor nos traz que representatividade é o tamanho que o corpus possui, assim sendo, quanto maior o corpus maior é a representatividade do mesmo. Ainda nos cita que, para saber a representatividade de um corpus, faz-se necessário saber de onde advém, no caso, no campo da linguística é impossível se mensurar, já que a sua dimensão é desconhecida. Contudo, a partir da probabilidade, podemos analisar a representatividade de um corpus de acordo com a frequência com que as palavras aparecem. Um corpus pode ser classificado como pequeno, se obtiver menos de 80 mil palavras; pequeno-médio, entre 80 a 250 mil palavras; médio, 250 mil a 1 milhão; médio-grande, 1 milhão a 10 milhões; e grande, 10 milhões ou mais de acordo com a quantidade de palavras encontradas.

Sardinha (2004, p. 145) nos apresenta a nomenclatura empregada na linguística de corpus para se definir o conteúdo e o propósito dos corpora e cita os tipos principais citados na literatura, que são:

Modos: falados (transcrição da fala) ou escritos;

Tempo: sincrônico, diacrônico, contemporâneo, histórico; 
Seleção: de amostragem (amostra finita da linguagem, é estático), monitor (dinâmico, reciclável), equilibrado (balanceado, distribuição de textos em quantidades semelhantes);

Conteúdo: especializado (gêneros), regionais ou dialetais, multilíngue;

Autoria: de aprendiz (falantes não-nativos), de língua nativa (falantes nativos);

Disposição interna: paralelo (original e tradução), alinhado/comparável;

Finalidade: de estudo (descrição de corpus), de referência (para contrastar com o corpus de estudo), de treinamento (para desenvolvimento de aplicações e ferramentas de análise).

Diante de tais apontamentos, utilizamos a linguística de corpus em nossa pesquisa para buscar os sentidos de currículo e de avaliação presentes nos documentos nacionais e locais sobre o Ensino Fundamental nos segmentos I e II.

\section{WordSmith Tools 6}

Atualmente existem diversos programas de computadores que auxiliam nas análises de copora. Na pesquisa em tela, usamos o WordSmith Tool 6 que, de acordo com Sardinha (2006, p.6), "é um conjunto de programas integrados ('suíte') destinado à análise linguística na frequência e na co-ocorrência de palavras em corpora".

No uso deste programa para análise de corpora, atemo-nos às ferramentas WordList, KeyWords e Concord que nos auxiliaram na análise, mediante os objetivos propostos e foram muito eficazes. Sardinha (2006, p.08) apresenta essas ferramentas como:

WordList : produz listas de palavras contendo todas as palavras do arquivo ou arquivos selecionados, elencadas em conjunto com suas frequências absolutas e percentuais. Também compara listas, criando listas de consistência, onde é informado em quantas listas cada palavra aparece.

Concord: realiza concordâncias, ou listagens de uma palavra específica (o 'nódulo', node word ou search word) juntamente com parte do texto onde ocorreu. Oferece também listas de colocados, isto é, palavras que ocorreram perto do nódulo.

KeyWords: extrai palavras de uma lista cujas frequências são estatisticamente diferentes (maiores ou menores) do que as frequências das mesmas palavras num outro corpus (de referência). Calcula também palavras-chave chave, que são chave em vários textos.

Tais ferramentas apresentam outras aplicabilidades que nos levam a um melhor entendimento de sua funcionalidade, e assim as descrevemos (SARDINHA, 2006, p. 10) 


\section{Wordlist:}

- Lista de palavras individuais (wordlist)

- Lista de multipalavras (wordlist, clusters activated)

- Lista de palavras de consistência individuais (detailed consistency)

- Lista de multipalavras de consistência (detailed consistency, clusters activated)

- Lista de dimensões e densidade lexical (statistics)

\section{Keywords}

- Lista de palavras-chave (keywords)

- Banco de dados de listas de palavras-chave (database)

- Lista de palavras-chave chave (key keywords)

- Lista de palavras-chave associadas (associates)

- Lista de agrupamentos textuais (chunks)

- Gráfico de distribuição de palavra-chave (keyword plot)

- Listagem de elos entre palavras-chave (keywords plot links)

\section{Concord}

- Concordância (concordance)

- Lista de colocados (collocates)

- Lista de agrupamentos lexicais (clusters)

- Lista de padrões de colocados (patterns)

- Gráfico de distribuição de palavra de busca (plot)

\section{Coleta de Dados}

Para efetuar a coleta de dados de nossa pesquisa fizemos, a priori, alguns atos preparatórios, que ocorreram, primeiramente, com as pesquisas bibliográficas para possuir certo domínio da temática antes de sair em campo. Para efetuar a pesquisa nas Escolas Públicas da Rede Municipal de Ensino de João Pessoa/PB, nos dirigimos ao Centro Administrativo Municipal, onde fomos até a Secretaria de Educação e Cultura (SEDEC) e protocolamos a requisição de autorização de pesquisa no dia 11 de março de 2015. Juntamente com a requisição de autorização foi apresentado o projeto de pesquisa a ser efetuado e a aprovação pelo Comitê de Ética da UFPB para a execução da pesquisa (Anexo 1 Requerimento de Solicitação de Pesquisa e Autorização de Comitê de Ética e Protocolo na PMJP) e recebemos o protocolo de número "2015/026283".

Após diversas idas à SEDEC, obtivemos a autorização para a execução da pesquisa em 15 de junho de 2015. Tal demora da Edilidade Municipal em autorizar a pesquisa levou a um atraso na sua execução, contudo sem resultar danos para a qualidade da pesquisa. 
As Escolas Públicas Municipais estão divididas em nove polos, como forma de facilitar a administração das mesmas de acordo com a realidade das comunidades de cada polo. A rede municipal de ensino possui Centros de Referência no Ensino Infantil, Escolas de Ensino Fundamental I e Escolas de Ensino Fundamental I e II. Em nossa pesquisa, buscamos as escolas que possuem o Ensino Fundamental I e II para, assim, analisar quais os sentidos de currículo e de avaliação presentes nos PPPs dessas escolas e de seu corpo docente.

Dentro das escolas que se enquadravam nos parâmetros supracitados, buscamos aquelas que se disponibilizassem para nos receber e permitir que efetuássemos a pesquisa, uma vez que nem todas as escolas que procuramos nos receberam, algumas alegando que estavam ocupadas em projetos e outras em que os professores se negaram a nos responder a entrevista. Outro ponto que dificultou nosso estudo foram diretores que não nos disponibilizaram o PPP de suas escolas, havendo escolas, inclusive, onde chegamos a ouvir que o PPP de uma escola " $X$ " foi feito por profissionais e que, antes de dar para um estagiário, teria que consultar quem o fez.

Após tantos entraves burocráticos e administrativos, conseguimos efetuar as entrevistas com dois professores de uma única escola que contempla o ensino fundamental I e II segmentos. Os professores, um que leciona o ensino fundamental I, chamaremos de professor " $A$ " e outra que leciona ao ensino fundamental II, chamaremos de professor "B". O Professor " $A$ " é licenciado em história e em pedagogia com especialização em pedagogia sexual, leciona na escola há mais de vinte anos e também leciona no ensino médio pela rede estadual de ensino. Este, além de ensinar no ensino fundamental, já lecionou as disciplinas de história, português, sociologia e filosofia no ensino médio em outra escola. A entrevista com o professor " $A$ " durou 5 minutos e 52 segundos. O Professor " $B$ " possui sua primeira formação no magistério, ainda possui graduação em Ciências Econômicas pela UFPB, onde foi pesquisadora PIBIC e atuou no PETI, possui especialização na área de sociologia política, mestrado em sociologia e doutorado em teoria social. Esta lecionou por três anos como professora substituta da UFPB, é recém-concursada na Prefeitura Municipal de João Pessoa, está há seis meses está atuando como professora do ensino fundamental Il e, além do labor na escola, ainda leciona em algumas faculdades particulares. A entrevista com o professor "B" durou 9 minutos e trinta e cinco segundos.

\section{Teoria do Discurso}

Para a análise dos dados computados pelo estudo da linguística de corpus, lançamos mão da Teoria do Discurso, teoria esta cunhada por Laclau \& Mouffe (2004) e Laclau (2005). Este é o nosso primeiro contato com essa Teoria e, devido à complexidade de tais obras e o tempo exequível de execução da pesquisa em tela, usamos autores que estudam e nos trazem em suas obras os seus entendimentos sobre tal teoria, a exemplo de Pereira (2009a, b), Mendonça (2009), Ferreira (2011) e outros, na certeza de que daremos continuidade aos estudos dessa teoria para aprofundamento em pesquisas futuras.

Mendonça nos afirma que "a teoria do discurso tem o potencial de ser uma ferramenta de compreensão do social, uma vez que seu próprio entendimento dá-se, nesta perspectiva, a partir da construção de ordens discursivas, sendo a questão do poder central e constituidora de relações sociais" (2009, p.153-154).

Apontando para a compreensão da Teoria do Discurso, Ferreira (2011) destaca o princípio de descentramento do sujeito. De acordo com o autor, as relações contemporâneas possuem uma complexidade que coloca em uma situação difícil um centro fixo constituidor de identidades, havendo, portanto, uma pluralidade de centros. 
Laclau (2005, p. 92 apud Pereira, 2009a, p.119) "assume que o discurso constitui o terreno primário de constituição da objetividade como tal. $\mathrm{O}$ discurso não está restrito à fala $\mathrm{e}$ à escrita, mas a um complexo de elementos no qual as relações jogam um rol constitutivo".

O discurso, de acordo com Mendonça (2009), é uma categoria que une palavras e ações e, assim sendo, possui natureza material, não possuindo natureza ideal, posto que discurso é prática, o que nos faz pensar em uma prática discursiva, já que qualquer ação feita por sujeitos, identidades e grupos sociais são ações significativas.

Analisar currículo dentro de um processo de redes de significação, para Pereira (2009b), é considerá-lo como prática discursiva, assim sendo, os discursos sobre o currículo não possuem uma pré-existência no processo relacional, e sim, são constituidores e constituídos no processo, em um jogo de equivalência e diferença por meio do discurso e sua prática discursiva.

O currículo enquanto discurso e prática discursiva se constitui e é constituído por um rol de objetos, de pessoas, de práticas culturais, relações sociais e de poder que objetivamente estão presentes, nesses espaços, onde ele se desenvolve. Essas práticas discursivas se formam dentro e fora de uma relação de objetividade. O discurso é palavra e ação (Pereira, 2009b, p.120).

Firino, Santos e Lopes (2014) apontam que tradicionalmente os discursos sobre currículo possuíam conceitos pré-definidos, mas, se os considerarmos como significantes vazios, não podemos mais considerá-los dessa forma, ou seja, de maneira acabada, permanente, e a mudança de seus sentidos é constituída por mudanças sociais.

O significante vazio aponta-nos Mendonça (2009, p.162), "ocorre quando um discurso universaliza tanto seus conteúdos a ponto de ser impossível de ser significado de forma exata". Continuando, o autor nos traz que, obstando um significante vazio ser um significante sem significado, em razão de possuir vários significados em uma só palavra como natureza, faz com que este esvazie seu conteúdo específico, possibilitando, assim, a percepção de seus limites que são sempre antagônicos. E termina asseverando que "os limites de um discurso buscam sempre subverter seus sentidos, sendo, portanto, negativos à constituição desses" (MENDONÇA, 2009, p.163).

\section{RESULTADOS}

\section{Sentidos de Avaliação nos Documentos Oficiais sobre o Ensino Fundamental}

Ao fim das análises dos documentos oficiais norteadores da educação brasileira, pudemos perceber que avaliação está presente em todos os textos, aparecendo 269 vezes nos textos usados como corpus de nossa pesquisa, estando, assim, na 12a posição de palavras citadas em todos os documentos analisados, conforme verificado na Tabela 1. Na verificação das palavras-chaves presentes nos documentos sobre o ensino fundamental, em nível nacional e local, avaliação aparece como a palavra-chave com décima segunda maior frequência nesses documentos. A partir desses dados, partimos para a verificação das concordâncias com o nódulo "avaliação". 
Tabela 1 - Lista de sentidos de avaliação presentes nos documentos nacionais

\begin{tabular}{ccccc}
\hline PALAVRA & FREQUÊNCIA & \%F & TEXTOS & \% \\
\hline ENSINO & 831 & 0,82 & 8 & 100,00 \\
\hline EDUCAÇÃO & 742 & 0,74 & 8 & 100,00 \\
COMO & 673 & 0,67 & 8 & 100,00 \\
\hline ESCOLA & 491 & 0,49 & 8 & 100,00 \\
\hline ALUNOS & 464 & 0,46 & 6 & 75,00 \\
\hline APRENDIZAGEM & 430 & 0,43 & 8 & 100,00 \\
\hline ESCOLAR & 383 & 0,38 & 8 & 100,00 \\
\hline FUNDAMENTAL & 337 & 0,33 & 8 & 100,00 \\
\hline PROCESSO & 312 & 0,31 & 6 & 75,00 \\
\hline CONTEÚDOS & 296 & 0,29 & 8 & 100,00 \\
AVALIAÇÃO & 269 & 0,27 & 8 & 100,00 \\
\hline DESENVOLVIMENTO & 268 & 0,27 & 8 & 100,00 \\
\hline ALUNO & 265 & 0,26 & 7 & 87,50 \\
\hline TRABALHO & 236 & 0,23 & 8 & 100,00 \\
PROFESSOR & 233 & 0,23 & 8 & 100,00 \\
\hline
\end{tabular}

Fonte: Organizada pelos/as Autores/as, com dados do WordSmith Tool 6.

Ao analisar a concordância de "avaliação" na ferramenta Concord do WordSmith Tools 6 , foi verificado que tal palavra apresentava concordância com outras 256 palavras, das quais selecionamos as quinze que se apresentam vinculando sentido a "avaliação" com mais frequência e presentes em um número maior de textos, sendo elas presentes na Tabela 2. Tais concordâncias com o nódulo "avaliação" apresentam-se como os significantes que dão sentido ao nódulo analisado. Apresentamos na Figura 1 os sentidos de avaliação que podemos encontrar analisando os documentos nacionais e locais que versam sobre o ensino fundamental.

Figura 1- Sentidos de avaliação encontrados nos documentos nacionais

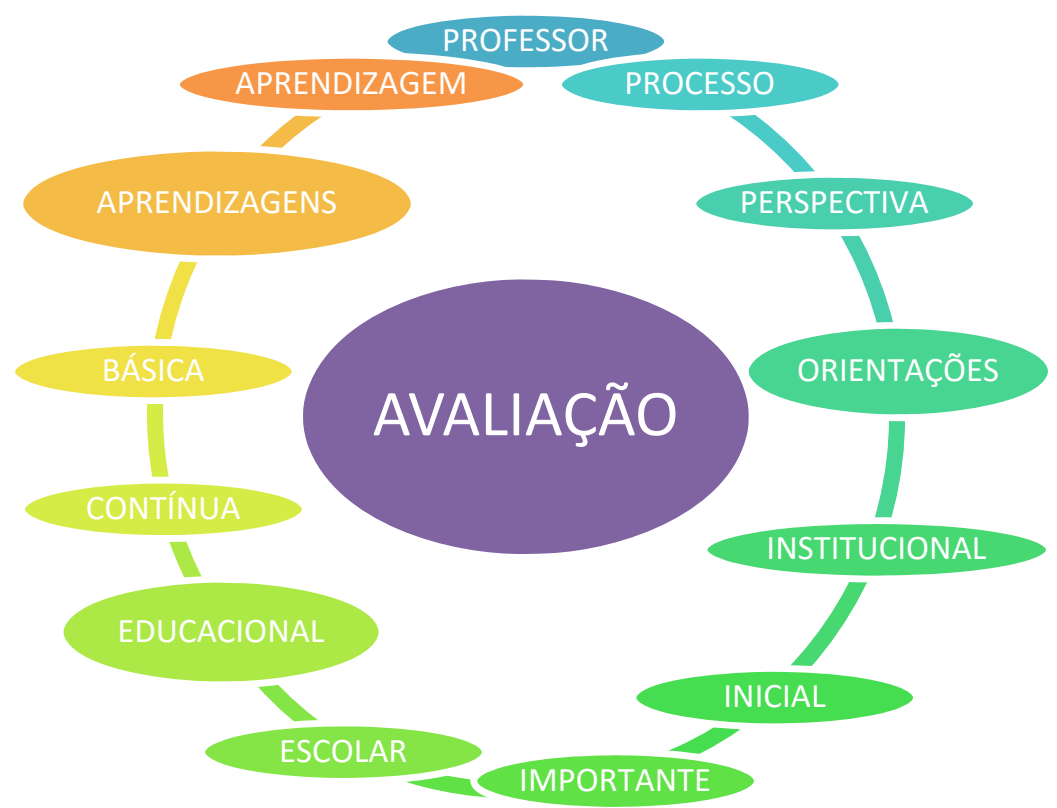

Fonte: Organizada pelos/as Autores/as. 
Tabela 2 - Concordâncias do nódulo "avaliação"

\begin{tabular}{cccccc}
\hline PALAVRA & R1 & R2 & R3 & R4 & R5 \\
\hline PROFESSOR & - & - & 2 & - & 4 \\
\hline PROCESSO & - & 4 & 2 & - & 2 \\
PERSPECTIVA & - & 6 & - & - & - \\
\hline ORIENTAÇÕES & 2 & 4 & - & - & 2 \\
INSTITUCONAL & 4 & - & - & - & 1 \\
INICIAL & 6 & 2 & - & - & - \\
IMPORTANTE & - & 2 & - & 2 & 2 \\
ESCOLAR & 2 & - & 5 & - & 1 \\
ESCOLA & - & 2 & 1 & - & 3 \\
EDUCACIONAL & 4 & - & 1 & - & - \\
EDUCAÇÃO & - & 6 & - & 5 & - \\
CONTÍNUA & 6 & - & - & - & - \\
BÁSICA & - & - & 4 & - & 3 \\
\hline APRENDIZAGENS & - & 3 & 4 & - & - \\
APREDIZAGEM & - & 11 & - & - & - \\
\hline
\end{tabular}

Fonte: Organizada pelos/as Autores/as, com dados do WordSmith Tool 6.

\section{Sentidos de Avaliação nos Discursos dos Docentes}

Aplicando este sub-corpus no WordSmith Tools, verificamos que avaliação apresenta concordância com os seguintes termos: final, âmbito, cognitivo, aprendizagem e contínua (ver Tabela 3). E, portanto, assumimos como estes os sentidos de avaliação presentes nos discursos dos docentes, assim como demonstramos na Figura 2.

Tabela 3 - Concordância de sentidos de avaliação presentes no discurso dos docentes

\begin{tabular}{cccccc}
\hline Word & R1 & R2 & R3 & R4 & R5 \\
\hline AVALIAÇÃO & - & - & - & - & - \\
FINAL & 2 & - & - & - & - \\
ÂMBITO & - & - & - & 2 & - \\
COGNITIVO & - & - & - & - & 2 \\
APRENDIZAGEM & - & 2 & - & - & - \\
CONTINUA & 2 & - & - & - & - \\
\hline
\end{tabular}

Fonte: Organizada pelos/as Autores/as, com dados do WordSmith Tool 6.

Analisando os discursos dos docentes percebemos que a palavra "avaliação" é a trigésima terceira palavra em número de frequência presente no discurso dos docentes entrevistados, sendo citadas 6 vezes no somatório das entrevistas realizadas (ver Tabela 4).

Percebemos, ainda, que, dos cinco significantes de avaliação presentes nos discursos dos docentes, três estão em comum com os sentidos de avaliação presentes nos documentos oficiais, que são: final, aprendizagem e contínua. 
Figura 2 - Sentidos de avaliação presentes no discurso dos docentes

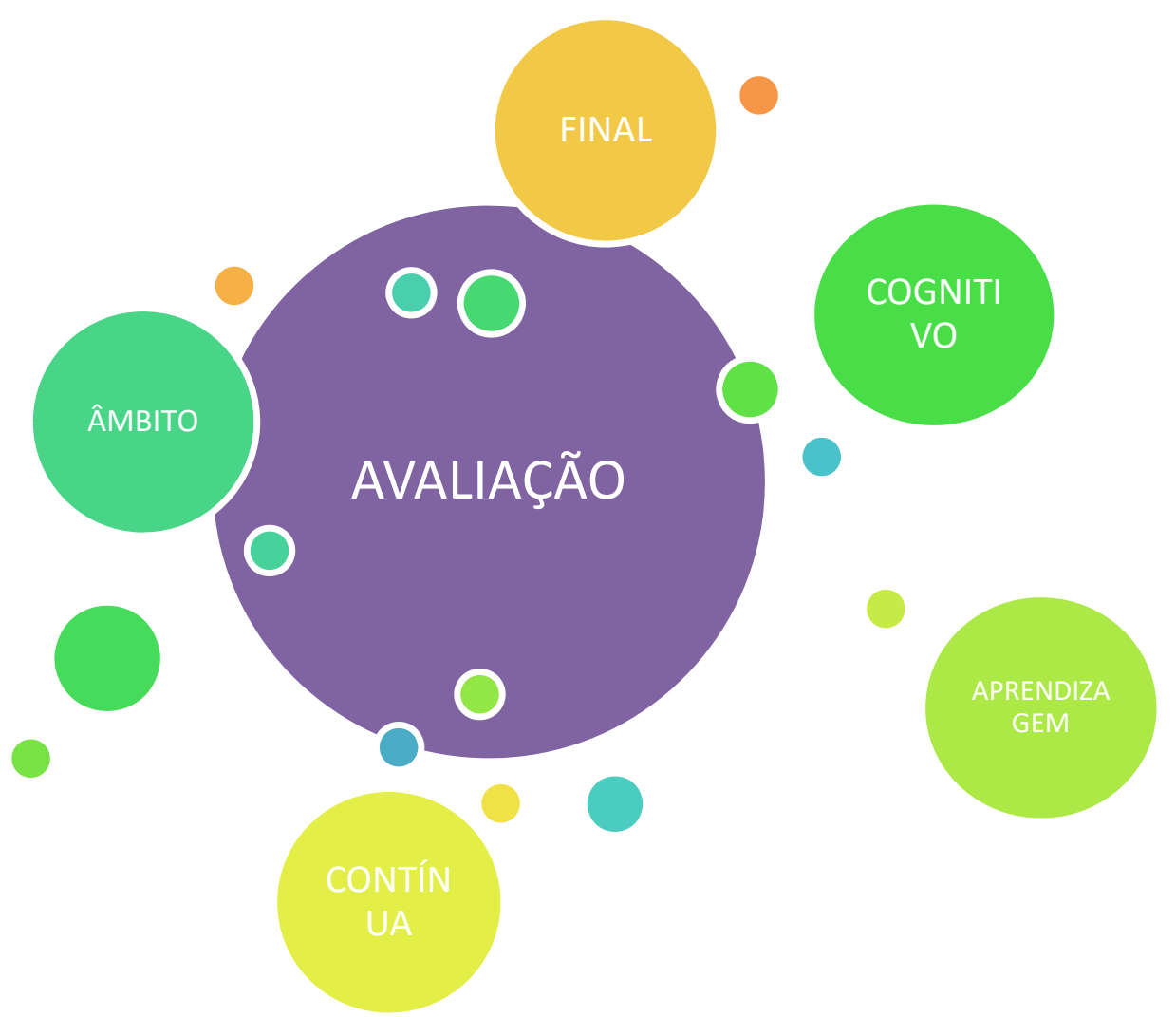

Fonte: Organizada pelos/as Autores/as.

\section{DISCUSSÕES}

\section{Currículo e Avaliação: entrelaços e sentidos articulados}

As teorias sobre o currículo surgem a partir da especialização do currículo como campo profissional e de estudos e pesquisas e, além disso, as professoras e professores sempre estiveram de alguma forma ligados ao currículo, antes mesmo do seu surgimento como campo específico de estudo (SILVA, 2013).

Nós adotamos, entre tantas teorias existentes sobre o currículo, a posição de Pereira (2009a, p.170) que assume "o currículo como redes de significação permeadas por relações de poder, e, em constante processo de deslocamento. Esses deslocamentos tornam-se importantes porque dão significação múltipla à prática social e cultural nele produzida".

As autoridades, professores, gestores, pais, alunos e sociedade em si possuem vários questionamentos sobre o currículo, o que faz com que reflitamos quais são as concepções sobre o currículo. Assim, apresenta-nos Moreira e Candau (2007, p. 18) como sendo:

a) os conteúdos a serem ensinados e aprendidos, as experiências de aprendizagem escolares a serem vividas pelos alunos;

b) os planos pedagógicos elaborados por professores, escolas e sistemas educacionais; 
c) os objetivos a serem alcançados por meio do processo de ensino;

d) os processos de avaliação que terminam por influir nos conteúdos e nos procedimentos selecionados nos diferentes graus de escolarização.

Tabela 4 - Lista de palavras presentes no discurso dos docentes

\begin{tabular}{|c|c|c|c|c|}
\hline Word & Freq. & $\%$ & Texts & $\%$ \\
\hline NÉ & 42 & 2,12 & 2 & 100,00 \\
\hline EU & 38 & 1,92 & 2 & 100,00 \\
\hline GENTE & 34 & 1,71 & 2 & 100,00 \\
\hline PRA & 28 & 1,41 & 2 & 100,00 \\
\hline TAMBÉM & 26 & 1,31 & 2 & 100,00 \\
\hline DIZER & 18 & 0,91 & 2 & 100,00 \\
\hline ENTÃO & 18 & 0,91 & 2 & 100,00 \\
\hline VAMOS & 18 & 0,91 & 2 & 100,00 \\
\hline COMO & 14 & 0,71 & 2 & 100,00 \\
\hline AQUI & 12 & 0,60 & 2 & 100,00 \\
\hline AULA & 12 & 0,60 & 2 & 100,00 \\
\hline DIFICULDADE & 12 & 0,60 & 2 & 100,00 \\
\hline ESSA & 12 & 0,60 & 2 & 100,00 \\
\hline FUI & 12 & 0,60 & 2 & 100,00 \\
\hline MOMENTO & 12 & 0,60 & 2 & 100,00 \\
\hline REALIDADE & 12 & 0,60 & 2 & 100,00 \\
\hline CRIANÇA & 10 & 0,50 & 2 & 100,00 \\
\hline ÂMBITO & 8 & 0,40 & 2 & 100,00 \\
\hline CASA & 8 & 0,40 & 2 & 100,00 \\
\hline COGNITIVO & 8 & 0,40 & 2 & 100,00 \\
\hline DEPOIS & 8 & 0,40 & 2 & 100,00 \\
\hline DOIS & 8 & 0,40 & 2 & 100,00 \\
\hline ENSINO & 8 & 0,40 & 2 & 100,00 \\
\hline ESCOLAR & 8 & 0,40 & 2 & 100,00 \\
\hline FAZER & 8 & 0,40 & 2 & 100,00 \\
\hline MAS & 8 & 0,40 & 2 & 100,00 \\
\hline PRÁTICAS & 8 & 0,40 & 2 & 100,00 \\
\hline PRIMEIRO & 8 & 0,40 & 2 & 100,00 \\
\hline PROCESSUAL & 8 & 0,40 & 2 & 100,00 \\
\hline ACHO & 6 & 0,30 & 2 & 100,00 \\
\hline ALUNO & 6 & 0,30 & 2 & 100,00 \\
\hline ANO & 6 & 0,30 & 2 & 100,00 \\
\hline AVALIAÇÃO & 6 & 0,30 & 2 & 100,00 \\
\hline
\end{tabular}

Fonte: Organizada pelos/as Autores/as, com dados do WordSmith Tool 6.

Para compreendermos o contexto em que o currículo e a avaliação apresentam-se em nosso trabalho, é importante destacarmos que os documentos oficias apontam para a organização do ensino fundamental como o ensino em ciclos, e tal posicionamento é adotado 
pelas escolas da rede municipal de ensino de João Pessoa, o que nos leva a fazer algumas considerações sobre o ensino em ciclos, sobre o currículo e a avaliação nesse contexto.

Os PCNs destacam um posicionamento claro quanto à adoção da estruturação do ensino fundamental em ciclos, apresentando como justificativa para tal decisão que essa proposta permite uma redução nas pressões envolvendo ao tempo escolar e adotando medidas educativas mais adequadas à aprendizagem e avaliação dos alunos. No mesmo sentido, Mainardes (2010) nos aponta que a escola em ciclos é progressista e justificada por diferentes razões, entre elas, por ser uma alternativa ao fracasso escolar e à exclusão, como a possibilidade de construção de uma escola democrática e, ainda, uma forma de garantir a aprendizagem e o atendimento de acordo com as necessidades diferentes de aprendizagem dos alunos.

Sobre a avaliação no contexto das políticas de ciclos, Mainardes (2010) aponta que diversos pesquisadores defendem que há a possibilidade de permitir o abono progressivo da avaliação classificatória e, assim, impulsionar a incorporação de práticas avaliativas qualitativamente superiores, como, por exemplo, a avaliação formativa, a avaliação emancipatória, a avaliação diagnóstica, a avaliação dialógica, entre outras formas de avaliação presentes em documentos oficiais e em pesquisas acadêmicas.

Fernandes e Freitas (2007) afirmam que, mesmo quando a organização curricular é feita em ciclos e em progressão continuada, na qual se elimina o poder de reprovação dos instrumentos avaliativos, não quer dizer que não haja uma avaliação, pois, segundo o autor, normalmente há uma noção reduzida de avaliação como sendo a medição de competências e habilidades que um estudante possui ao final de um determinado período, ou seja, a avaliação servindo como uma forma de verificar se o estudante aprendeu ou não o conteúdo ensinado. Os referidos autores nos apontam que avaliação é bem mais ampla e que envolve, também, outras esferas da sala de aula.

Dentro de tantas formas existentes de avaliação, percebemos um destaque na avaliação formativa que Fernandes e Freitas (2007, p.22) sintetizam como sendo "[...] aquela em que o professor está atento aos processos e às aprendizagens de seus estudantes. O professor não avalia com o propósito de dar uma nota, pois dentro de uma lógica formativa, a nota é uma decorrência do processo e não o seu fim último".

Silva (2013) afirma que as discussões sobre o currículo trazem à tona discussões sobre os conhecimentos escolares, os processos de ensino-aprendizagem, as relações sociais que formam o ambiente onde há o ensino e a aprendizagem e, ainda, sobre as transformações propostas a serem feitas nos estudantes, sobre os valores que desejamos cultivar e as identidades que serão construídas. Finalizando, a autora traz que as discussões sobre questões curriculares são marcadas por discussões sobre conhecimento, verdade, poder e identidade.

Podemos perceber o imbricamento entre currículo, através dos apontamentos de Silva, e avaliação, a partir do posicionamento de Fernandes e Freitas (2007), que nos informam que o professor, algumas vezes, não avalia somente o conhecimento do estudante adquirido em um processo de aprendizagem, mas é levando em consideração seus valores ou atitudes. $E$, portanto, a conceituação de avaliação escolar, feita nas salas de aula, deve-se levar em consideração, entre tantos aspectos, os seguintes: o conhecimento aprendido pelo estudante e seu desenvolvimento, o comportamento do estudante e seus valores e atitudes.

Analisando a "avaliação" tanto como discurso, presente nos documentos que regem o ensino fundamental, e como prática, presente nos discursos dos docentes do ensino fundamental da rede de ensino público de João Pessoa, chegamos aos sentidos para avalição como sendo: professor, processo, perspectiva, orientações, institucional, inicial, importante, 
escolar, educacional, contínua, básica, aprendizagem, final, cognitivo e âmbito. Assim, como pudemos visualizar na figura a seguir (Figura 3 ).

Figura 3 - Sentidos de avaliação presentes nos documentos nacionais, locais e nos discursos dos docentes

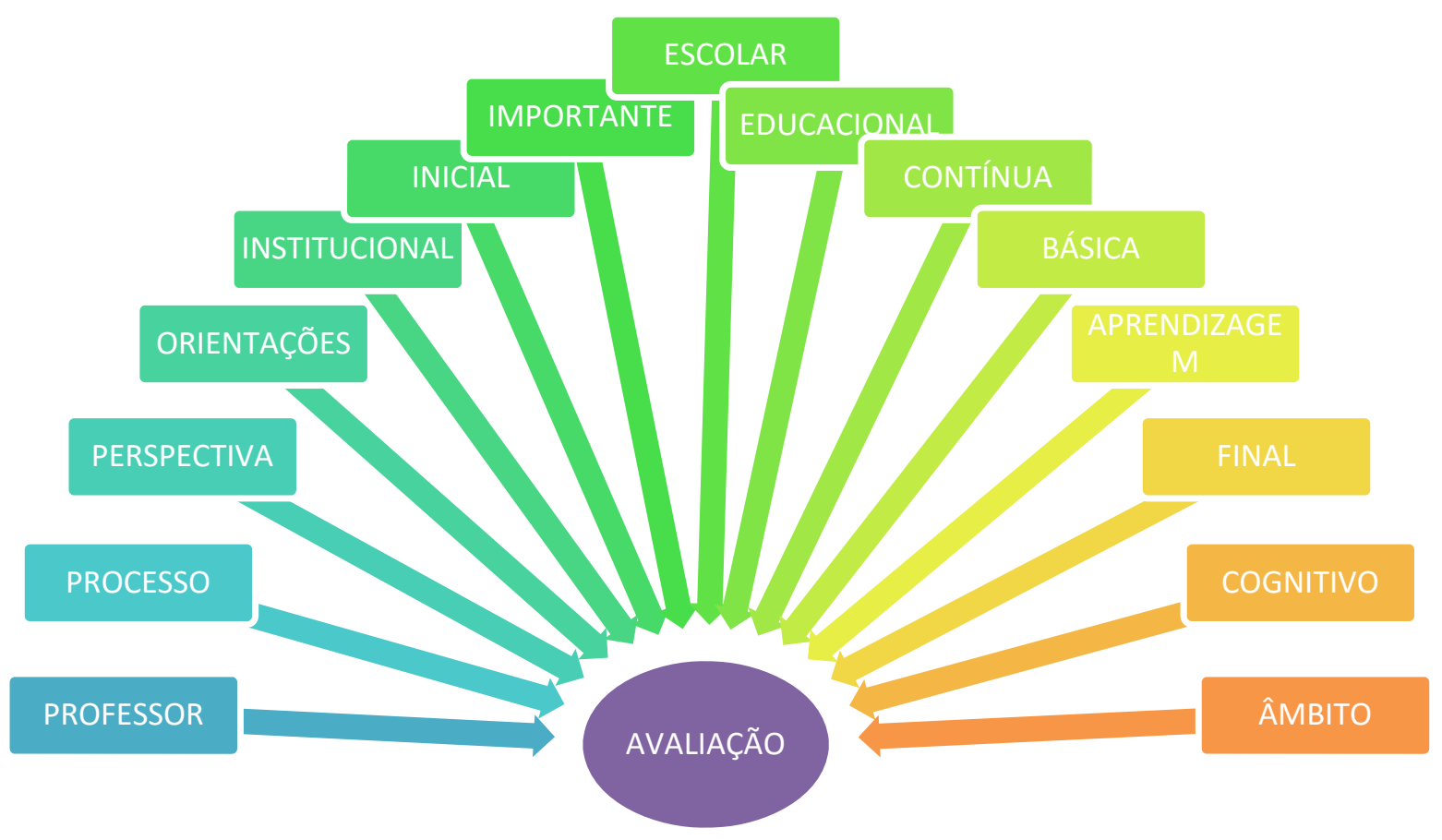

Fonte: Organizada pelos/as Autores/as

Nossa pesquisa é uma continuidade da pesquisa realizada por Pereira et al (2014), com o tema: OS SENTIDOS DO CURRÍCULO NAS ESCOLAS DA REDE MUNICIPAL DE ENSINO DE JOÃO PESSOA/PB: Análises Discursivas dos sentidos e significados de currículo, cujos resultados foram publicados como relatório de PIBIC no período 2013/2014. Em seu relatório, nos foi apresentado como sentidos de currículo presentes na Rede Municipal de Ensino de João Pessoa: ação, construção, conhecimento, cultura, ensino, fazer, guia, instrumento, processo, produção, visão.

Para além do imbricamento teórico entre currículo e avaliação, percebemos, ainda, uma aproximação clara entre os sentidos de currículo e os sentidos de avaliação nos discursos analisados. Mas, além da aproximação dos significantes dos nódulos "currículo" e "avaliação", ambos são significantes vazios, pois é impossível a delimitação dos sentidos dado aos mesmos, havendo, ainda, a possibilidade de variação dos sentidos com o passar do tempo e outras variantes que possam existir. Havendo não só o imbricamento entre currículo na teoria, no discurso, como também na prática dos docentes.

Portanto, tanto currículo como avaliação são práticas discursivas, posto que ambas são materiais e constituem e são constituídas no processo. E ambas possuem um significante vazio, dada a impossibilidade de se limitar os seus sentidos. 


\section{CONCLUSÕES}

Nesta pesquisa pudemos verificar as congruências existentes entre os sentidos de currículo e avaliação e a forma como os seus sentidos se imbricam. Foram analisados os documentos nacionais norteadores do ensino fundamental, o Plano Municipal de Educação em vigor, como documento local norteador do ensino fundamental, o Projeto Político Pedagógico de uma das escolas da rede municipal de ensino e, por fim, as entrevistas com docentes, como forma de verificar a prática sobre currículo e avaliação no ensino fundamental.

Quanto aos documentos que versam sobre a educação, é importante lembrar que estamos em um momento de transição na construção dos mesmos. No ano de 2014 foi aprovado um novo Plano Nacional de Educação, que trouxe algumas novidades para a educação brasileira, entre as quais há a Base Nacional Comum Curricular que têm por objetivo que as escolas de todo o Brasil tenham uma mesma base na construção de seus currículos. $O$ novo PNE trouxe como consequência a exigência da construção de um novo Plano Estadual de Educação e de um novo Plano Municipal de Educação. No Estado da Paraíba, o Plano Estadual de Educação foi feito e sancionado pelo Governo do Estado, mas, no caso do Plano Municipal de Educação, ele foi aprovado pela Câmara Municipal, porém ainda não sancionado pela edilidade municipal e, portanto, ainda não estando em vigor como um documento norteador da educação.

Tais novos documentos norteadores da educação necessitam de um tempo para que haja uma transição/adaptação das escolas, possivelmente a partir de 2016, haja alterações nos PPPs das escolas, já constando as alterações previstas no novo Plano Nacional de Educação e nos planos estaduais e municipais.

Na pesquisa realizada pudemos perceber haver uma consonância entre o previsto nos documentos nacionais da educação, em relação aos sentidos de currículo e de avaliação, com os documentos locais e os PPPs das escolas da rede municipal de ensino, assim como nos discursos dos docentes da rede municipal, como visto através das entrevistas feitas com os mesmos. Contudo, pesquisas futuras poderão averiguar como o previsto nos documentos oficiais da educação se aplica no dia a dia das escolas e se há, realmente, uma consonância na prática da sala de aula com o que foi dito no discurso dos docentes e dos documentos oficiais.

No decorrer de nossa pesquisa surgiram alguns questionamentos que merecem uma melhor reflexão e, até mesmo, novas pesquisas mais aprofundadas, questões essas que não puderam ser respondidas neste momento, como podemos exemplificar: a que ponto as dificuldades encontrados na infraestrutura das escolas bem como o não planejamento de uma aplicação justa de avaliação, atrapalham o processo de ensino aprendizagem? Como o currículo está posto na prática docente e como ele chega de fato ao seu destino final? Os métodos avaliativos utilizados pelos docentes possuem consonância com as propostas dos teóricos em avaliação?

Concluímos que todos os objetivos que propusemos investigar foram alcançados, analisando os sentidos de currículo e avaliação presentes nos documentos oficiais, nos documentos locais e nos discursos dos docentes da rede municipal de ensino de João Pessoa/PB. Tais sentidos percebidos nos leva a conclusão de que a educação apresenta-se sempre em constante processo de adaptação e renovação, assim como nossa sociedade e, por isso, as pesquisas nessa área nunca serão conclusas, pois novos desafios sempre surgirão para o currículo, para a avaliação e para a prática docente. 


\section{REFERÊNCIAS}

BRASIL. Diretrizes Curriculares Nacionais da Educação Básica. Brasília- DF, 2013.

Lei 9.394, de 20 de dezembro de 1996. Estabelece as Diretrizes e Bases da Educação Brasileira, 1996. Disponível em: < http://www.planalto.gov.br/ccivil_03/LEIS/L9394.htm> Acesso em 10 de abr. 2015.

Parâmetro Curriculares Nacionais. Brasília- DF, 1996.

ESTEBAN, Maria Tereza. DISCURSOS SOBRE AVALIAÇÃO DA APRENDIZAGEM: indagações e potencialidades. In: PEREIRA, Maria Zuleide da Costa et al (organizadoras). Diferenças nas Políticas de Currículo/. João Pessoa, PB: ED. Universitária da UFPB, 2010. p. 305-319.

FERNANDES, Claúdia de Oliveira, FREITAS, Luiz Carlos. Currículo e Avaliação. In: BEAUCHAMP, Jeanete, PAGEL, Sandra Denise, NASCIMENTO, Aricélia Ribeiro do (orgs.). Indagações sobre currículo. Brasília : Ministério da Educação, Secretaria de Educação Básica, 2007.

FERREIRA, Fabio Alves. Para Entender a Teoria do Discurso de Ernesto Laclau. Revista Espaço Acadêmico. n. 127, Dez/2011, p. 12- 18, 2001.

FIRINO, D.L.S, SANTOS, G.M., LOPES, S.A.. Sentidos de Currículo e Cultura na Proposta Curricular do Município de João Pessoa/PB. In: PEREIRA, Maria Zuleide da Costa, ALBINO, Ângela Cristina Alves. Ensaios Sobre Questões Curriculares, Editora UFPB: Paraíba, 2014. p. 189-285

GONÇALVES, Elisa Pereira. Iniciação à Pesquisa Científica. 3. Ed. Campina, SP: Editora Alinea, 2003.

JOÃO PESSOA/PB, Lei 9.864, de 27 de Dezembro de 2002. Plano Municipal de Educação. Jan, 2003.

LACLAU, Ernesto. La Razón Populista. Buenos Aires: Fondo de Cultura Económica de Argentina, 2005.

Chantal Mouffe. HEGEMONIA Y ESTRATÉGIA: SOCIALISTA: hacia una radicalización de la democracia. Fondo de Cultura Económica de Argentina, 2004.

MACORNI, Marina de Andrade, LAKATOS, Eva Maria. Fundamentos de Metodologia Científica 1. - 5. ed. - São Paulo : Atlas 2003.

MAINARDES, Jefferson. A escola em ciclos e os discursos sobre a avaliação da aprendizagem. In: PEREIRA, Maria Zuleide da Costa et al (organizadoras). Diferenças nas Políticas de Currículo. João Pessoa, PB: ED. Universitária/ UFPB, 2010. p. 321-339

MENDONÇA, Daniel. Como Olhar "O Político" a Partir da Teoria do Discurso. Revista Brasileira de Ciência Política, no1, Brasília, Jan-Jun de 2009, p. 153-169, 2009.

MOREIRA, Antonio Flavio Barbosa, Candau, Vera Maria. Currículo, Conhecimento e Cultura. In: PAGEL, Sandra Denise, NASCIMENTO, Aricélia Ribeiro do (orgs.). Indagações sobre currículo. Brasília: Ministério da Educação, Secretaria de Educação Básica, 2007. 
PEREIRA, Maria Zuleide da Costa. A Centralidade da Pluralidade Cultural nos Debates Contemporâneos no Campo do Currículo. Currículo sem Fronteiras, v.9, n.2, p. 169-184, Jul/Dez, 2009a.

Currículo, Discurso, Discursos. In: MACEDO, Elizabeth, MACEDO, Roberto Sidnei, AMORIM, Antonio Carlos (organizadores). Discurso, texto, narrativa nas pesquisas em currículo. Campinas, SP: FE/UNICAMP, 2009b. p. 114-123

PEREIRA, Maria Zuleide da Costa, ROCHA, Nathalia Fernandes Egito. Os Sentidos do Currículo nas Escolas da Rede Municipal de Ensino de João Pessoa/PB: Análises Discursivas dos sentidos e significados de currículo. In: Relatório PIBIC 2013/2014. UFPB, 2014.

SARDINHA, Tony Beber. Linguística de Corpus: histórico e problemática. D.E.L.T.A. São Paulo, v. 16, n. 1, p. 323-367, 2000.

SARDINHA, Tony Beber. Linguística de Corpus. Barueri, São Paulo: Manole, 2004.

O banco de palavras-chave como instrumento de identificação de Palavras-Chave exclusiva no programa Wordsmith Tool Keyword. The Specialist, São Paulo, v. 27, n. 1, p. 1 19, 2006. letras, 2009.

Pesquisa em linguística de corpus com Wordsmith tools. Campinas, SP: Mercado de

SILVA, Tomaz Tadeu da. Documentos de identidade: uma introdução as teorias do currículo. 3.Ed. 4. Reimp. Belo Horizonte, MG: Autentica Editora, 2013. 